\title{
"Capacidade de Carga" como Paradigma de Gestão dos Impactos da Recreação e do Turismo em Áreas Naturais
}

\author{
"Carrying Capacity" as a Paradigm to Manage the \\ Impacts of Recreation and Tourism in Natural Areas
}

Paulo dos Santos Pires ${ }^{1}$

\begin{abstract}
RESUMO: A incorporação do conceito de capacidade de carga pelo turismo e pela recreação como atividades com grande interesse e atuação voltados para os ambientes naturais, vem proporcionando amplo e fértil campo de abordagem, particularmente no meio acadêmico. Nesse contexto, visando contribuir para a formação de uma base de conhecimentos na área, este artigo oferece aporte conceitual e metodológico centrado no paradigma da capacidade de carga, abrangendo seus enfoques e tipologias, bem como os métodos de gestão dos impactos que vêm sendo criados e aplicados sobretudo nos países desenvolvidos. Trata-se não apenas de uma varredura bibliográfica sobre o tema, mas de um esforço de sistematização e de delimitação do conteúdo pertinente em função do interesse e da necessidade de atuação investigativa que se verifica atualmente no meio acadêmico.
\end{abstract}

PALAVRAS-CHAVE: turismo e recreação; meio ambiente; impactos; capacidade de carga; gestão.

ABSTRACT: The incorporation of the concept of carrying capacity by the tourism and by the recreation while activities with great interest and performance based on the natural environments, is providing a wide and fertile approach field, particularly in the academic circle. In this context, seeking to contribute for the formation of a knowledgebase in the area, this paper offers

1. Engenheiro florestal. Professor e pesquisador do Curso de Pós-Graduaçāo (Stricto Sensu) em Turismo e Hotelaria da Universidade do Vale do Itajaí - univale. Bloco 4. Sala 303. Contato: Centro de Educação do Balneário Camboriú. 5ª Avenida, s/nº Bairro dos Municípios - 88330-000 - Balneário Camboriú -sc; e-mail: pspires@bc.univali.br. 
a conceptual and methodological contribution centered in the paradigm of the load capacity, embracing its focuses, typologies as well as the methods of administration of the impacts that have been created and applied above al at the developed countries. It is not just a bibliographical sweeping on the theme, but of a systematization and delimitation effort of the pertinent content, in function of the interest and of the need of research that is verified now in the academic circle identified above.

KEYWORDS: tourism and recreation; environment; impacts; carrying capacity; administration.

\section{Introdução}

O advento do conceito de capacidade de carga na esfera do turismo, não por coincidência, corresponde ao mesmo período em que despontaram de forma mais contundente, em várias partes do mundo, os efeitos negativos dos impactos decorrentes desse mesmo turismo. Nesse período correspondente à década de 1970 surgem, portanto, os primeiros estudos com o objetivo de produzir conhecimento, gerar metodologias e oferecer respostas tecnicamente respaldadas à inquietação então reinante: quantas pessoas um determinado local ou ambiente pode suportar antes que se deteriore ou se descaracterize de forma irreversível?

Apesar de a deflagração do turismo de massa e a conseqüente constatação de seus impactos ter-se destacado em destinos preferenciais, como as estações de férias (de verão e de inverno) no continente europeu e em outros balneários espalhados pelo mundo, o objeto desses primeiros estudos foi um tipo de destinação especial, ou seja, as áreas naturais protegidas, notadamente sob a forma de parques nacionais e categorias equivalentes. Nessas áreas, obviamente, a dimensão ambiental era restrita ao meio natural, mais propriamente aos seus componentes biofísicos (solos, água, vegetação, fauna).

Tem-se então um cenário de partida para a apresentação da presente abordagem de caráter conceitual e metodológico, cuja pretensão é colocar a "capacidade de carga" como paradigma ambiental contemporâneo e, por que não dizer, conservacionista, no centro de gravidade de um extenso e profícuo campo de interesse para o planejamento ambiental, que é o controle, ou mais propriamente, a gestão dos impactos das atividades humanas (no caso, o turismo e a recreação) sobre o meio ambiente, com ênfase para o ambiente natural.

Assim, esta abordagem estrutura-se em quatro momentos correspondentes aos itens capacidade de carga: amplitude conceitual; a abrangência de enfoques e tipos de capacidade de carga; a gestão sustentável da recreação e do turismo em áreas naturais; e avanços constatados e desafios a enfrentar. Tal segmentação busca dar forma à sistematização das informações, proporcionando também, a juízo do autor, uma seqüência lógica, na intenção de apresentar no conjunto, um corpo coerente de informações e enfoques analíticos sobre o tema central escolhido.

\section{Capacidade de carga: amplitude conceitual}

De início cabe considerar que se adotou genericamente o termo inglês carrying capacity com a sua tradução operacional para a língua vernácula, "capacidade de carga", ou a versão similar, "capacidade de suporte". Assim, tomados essencialmente no sentido operacional no âmbito do turismo, tais termos adquirem um significado equivalente, o qual poderia ser descrito basicamente como a capacidade que um determinado meio ou ambiente possui para suportar o afluxo de visitantes e turistas sem perder as características de sua originalidade ou ter ameaçada a sua integridade. Infere-se, portanto, a idéia da inevitabilidade do impacto humano sobre o meio, bem como a aceitação de que esse meio poderá absorver ou tolerar impactos que resultem em alterações aceitáveis, ou seja, não comprometedoras de referida originalidade ou integridade.

Como será possível perceber mais adiante, a amplitude de âmbitos (psicológico-perceptivo, ecológico, material, social etc.) em que se verificam os impactos decorrentes da presença de visitantes e da atividade turística, evidencia a não-adequação plena das expressões "capacidade de carga" e "capacidade de suporte" à linguagem corrente das ciências que os abarca. De qualquer forma, não se tem como objetivo aqui investir numa abordagem mais detida nesse sentido, mas apenas sinalizar para uma futura (possivelmente não tão distante) reconsideração sobre a adoção indiscriminada das referidas expressões.

Então, para o que importa nesta abordagem, tem-se que o conceito de "capacidade de carga" aplicado ao turismo e à recreação ganhou, efetivamente, impulso a partir da década de 1970 (Sowaman, 1987), como uma técnica para a gestão do turismo em ambientes sensíveis (Eagles, P. F. J. et al. 2002). Não por acaso, foi a partir desse período que começou a se evidenciar a amplitude e a magnitude dos impactos decorrentes do turismo sobre o ambiente natural e construído - o que vale dizer sobre a paisagem - pré-existente, nos destinos preferenciais do turismo de massa, que então se expandia e se impunha.

Posta essa situação, é possível então inferir que os referidos impactos poderão ser avaliados em relação à "capacidade de carga" do ambiente para absorvêlos (Mason, 1990) ou, como convém à expressão adotada, para "suportá-los". No mesmo sentido, Boullón e Otero (1995) reforçam tal concepção, quando afir- 
mam que "capacidade de carga" é um conceito que se refere às possibilidades de cada lugar (destino turístico) suportar uma determinada afluência de visitantes.

No período inicial transcorrido desde o advento da concepção da capacidade de carga turística e recreativa aplicada, sobretudo, a ambientes naturais (década de 1970), prevaleceu no bojo das iniciativas e experiências empreendidas nesse sentido a preocupação em relação a dois aspectos principais: a manutenção da integridade da base de recursos e a oferta de uma experiência recreativa de qualidade para os usuários (Sowaman, 1987). Tal preocupação refletiu-se nas próprias definições ou aproximações conceituais sobre capacidade de carga turística, encontradas na literatura que cobriu o período transcorrido até o início da década de 1990.

Assim, o conceito de capacidade de carga na fase pioneira de sua utilização em trabalhos voltados ao manejo de visitantes em parques e reservas naturais protegidos, notadamente nos EUA, foi definido de forma elementar por Wagar (1964) como "o nível de uso que uma área pode suportar sem afetar a sua qualidade". Mesmo passado um longo período, observamos que em certas definições o conceito não mudou na sua essência, como verificado na seguinte definição da Organização Mundial do Turismo - OMT $(1983)^{2}$ : capacidade de carga "é a capacidade de suporte ou tolerância de uma área para acolher um número de visitantes sem alterar o seu estado natural, o que implica um limite ao crescimento turístico em uma área sem que se modifique o seu entorno".

Porém, nesse mesmo período, o conceito apresenta evoluções que são expressas em definições como a de Boo (1990), para quem "capacidade de carga é a quantidade máxima de visitantes que uma área pode acomodar mantendo poucos impactos negativos sobre os recursos e, ao mesmo tempo, altos níveis de satisfação para os visitantes"; e a de Cerro (1993), para quem o conceito de capacidade de carga e sua aplicação no turismo "reside na necessidade de se determinar limites para as atividades turísticas e recreativas, sendo que a extrapolação de tais limites faz aumentar os riscos de saturação dos equipamentos turísticos, degradação do meio ambiente e redução da qualidade da experiência turística". Nessa mesma linha evolutiva, o Serviço Nacional de Parques ${ }^{3}$ dos EUA, em 1992, passou a conceber a capacidade de carga como "o tipo e nível de uso que pode ser conciliado enquanto sustenta os recursos desejados e as

2. OMT. Riesgos de saturación o de superación de la capacidad turística em los puntos de destino. Madrid. 50 p.

3. National Park Service. 1992. Process for adressing visitors carrying capacity in the national park system. Denver, U.s. Department of the Interior [s.n.]. condições recreativas que integram os objetivos da Unidade e os objetivos de manejo" (In: Takahashi, 1998).

Já sob a influência do paradigma do "desenvolvimento sustentável", consagrado na conferência Mundial sobre Meio Ambiente e Desenvolvimento em 1992 (Rio-92), constata-se uma ampliação das preocupações envolvendo a concepção de "capacidade de carga", agora incluindo também a questão sociocultural e econômica relativa às populações residentes nas destinações turísticas. Nesse sentido, o conceito de McIntyre e Hetherington, citados por Ceballos-Lascurain (1996), é bastante ilustrativo:

a capacidade de carga está representada pelo número máximo de uso turístico-recreativo, associado à sua infra-estrutura, que uma área pode acomodar. Se esse nível é ultrapassado pode ocorrer a deterioração dos recursos, a diminuição da satisfação do visitante e impactos adversos sobre a sociedade, cultura e economia locais.

Considerando esse mesmo período, Ceballos-Lascurain (1996) afirmou que as mais recentes definições sobre capacidade de carga incluem, pelo menos, quatro componentes básicos, a saber: os componentes biofísicos; os fatores socioculturais; os aspectos psicológicos dos visitantes; e o manejo como instrumento de controle e gestão das áreas visitadas:

- O componente biofísico da capacidade de carga está relacionado principalmente aos recursos naturais, estendendo-se também aos recursos nãonaturais (patrimônio histórico-cultural) na sua expressão física. A avaliação científica nesta área requer a participação de especialistas da área de ciências naturais e da terra;

- O componente sociocultural da capacidade de carga reconhece que poderão ocorrer impactos socioculturais negativos sobre a população local se o turismo exceder um determinado nível, embora, às vezes, seja difícil distinguir entre os impactos negativos causados estritamente pelo turismo ou por outras atividades humanas. A avaliação deste tipo de impactos e, por extensão, da capacidade de carga, em nível científico, requer a assessoria de profissionais das áreas das ciências sociais e humanas;

- O componente psicológico da capacidade de carga relaciona-se ao número máximo de visitantes para os quais uma área está apta a oferecer uma experiência turístico-recreativa satisfatória num determinado período. A capacidade de carga psicológica, neste caso, depende de cada área e de seus atrativos, e das características ou expectativas dos turistas. 
A avaliação desse componente prescinde, também, de profissionais das ciências sociais e humanas, com destaque para a psicologia;

- O componente do manejo e gestão da capacidade de carga se refere ao nível máximo de visitação que pode ser adequadamente manejado (mantido sob controle) numa determinada área. Este componente está intrinsecamente ligado ao tipo de facilidades físicas e de infra-estrutura disponíveis para os visitantes em uma área. O manejo e a gestão da capacidade de carga, neste caso, aponta para um envolvimento profissional e científico interdisciplinar.

Fica, portanto, reconhecida, a complexidade envolvida na questão da capacidade de carga turístico-recreativa, bem como a abrangência de aspectos pertinentes que dela decorrem, haja vista que, no relativo curto espaço de tempo desde a incorporação desse conceito pelo turismo, constatou-se uma evolução na forma de fazer uso das virtudes e, ao mesmo tempo, reconhecer as limitações impostas pelo advento desse paradigma por aqueles que em toda parte se dedicam a acompanhar, estudar e intervir, científica e profissionalmente, no processo de desenvolvimento do turismo e da recreação, sobretudo no tipo de espaço preferencial desse tipo de demanda, que são as áreas naturais protegidas - no Brasil, instituídas no Sistema Nacional de Unidades de Conservação.

\section{A abrangência de enfoques e tipos de capacidade de carga}

A observação atenta da maioria dos estudos e experiências relacionados à capacidade de carga realizados até o início da década de 1990 permitiu a Cerro (1993) enfocá-los a partir de uma dupla perspectiva: de um lado, os planejadores vêm tentando resolver a questão por meio da fixação de padrões de uso; de outro, os ecólogos vêm centrando sua atenção na análise dos efeitos físicos causados pela atividade turística no meio por ela sustentado; mais recentemente, está se trabalhando o conceito de capacidade de carga a partir também da reaçāo psicológica do usuário das destinações turísticas diante do fenômeno da aglomeração, bem como da sua interpretação em termos de satisfação ou insatisfação da experiência turística, fato já constatado pelas próprias conceituações anteriormente apresentadas.

Uma varredura, ainda que não exaustiva, na literatura (Sowaman, 1987; Mason, 1990; Cerro, 1993; Boullón, 1997) que registra estudos e experiências de capacidade de carga em distintas partes do mundo, permite identificar vários enfoques de abordagem do conceito. Nesse sentido, são identificadas a seguir, e apenas de forma conceitual, as suas principais derivações.
A. Capacidade de carga

- Objetiva identificar e valorar as transformações produzidas no ecossistema em conseqüência do uso recreativo ou turístico. Por esse conceito, a intensidade de uso é traduzida em número de usuários, no qual a extrapolação de um certo limite (a ser determinado de forma subjetiva de acordo com juízos de valor emitidos por profissionais ou planejadores) implica a deterioração ecológica do meio. Outra forma também utilizada dentro desse conceito consiste na determinação dos níveis de degradação ecológica que possam ser considerados aceitáveis, dentro dos quais é então fixado o número máximo de usuários para um determinado destino turístico - neste caso também de forma subjetiva. Nesse tipo de estudo pode-se utilizar como parâmetro de avaliação da capacidade ecológica o efeito do pisoteio sobre a vegetação e sobre a estrutura do solo (Cerro, 1993);

- Está relacionada ao número de dias por ano, ao número de visitantes simultâneos e à rotatividade diária que pode ser estabelecida numa área sem que se altere o seu equilíbrio ecológico. Para encontrar a capacidade ecológica de um ambiente natural, deve ser realizada uma pesquisa específica para cada caso, pois na natureza não existem situações perfeitamente idênticas para os inúmeros tipos diferenciados de ambientes naturais (Boullón, 1997);

- Está relacionada com o nível máximo de uso recreativo em termos de atividades que podem ser acolhidas numa área ou ecossistema, antes que ocorra um declínio inaceitável ou irreversível nos ecossistemas da referida área - Capacidade de Carga Ecológica (Sowaman, 1987);

- Relaciona-se ao nível máximo de atividade turística que uma destinação pode suportar antes que modificações na vegetação natural, nos solos, na topografia e nos habitats animais possam ocorrer - Capacidade de Carga Ecológica (Mason, 1990).

\section{B. Capacidade perceptiva / psicológica / social}

- Parte do pressuposto de que o grau de saturação de um recurso está relacionado com a qualidade da experiência recreativa. Assim, à medida que aumenta a intensidade de uso de um determinado lugar, diminui o nível de satisfação do usuário. No entanto, o grau de concentração percebido como nocivo varia substancialmente em função das características das pessoas (Cerro, 1993); 
- Refere-se ao número de visitantes que simultaneamente podem ser acolhidos numa área natural, garantindo a todos uma experiência satisfatória. Dependendo da qualidade do turista (observador, ator), a capacidade psicológica pode variar, por exemplo, de dez mil metros quadrados para um campista solitário, cem metros quadrados para aquele que se aloja em acampamentos com alta concentração de pessoas, a até vinte metros quadrados, os quais podem ficar reduzidos a um metro quadrado para pessoas que ocupam mirantes - Capacidade Psicológica (Boullón, 1997);

- Relaciona-se ao nível máximo de uso recreativo em termos de intensidade e de atividades, antes que haja um declínio na qualidade da experiência recreativa do ponto de vista dos participantes dessa experiência - Capacidade de Carga Social (Sowaman, 1987).

\section{Capacidade paisagística}

- Relaciona-se à capacidade da paisagem para absorver visualmente o uso turístico ou recreativo, ou seja, a sua capacidade de "esconder" os visitantes e suas atividades num determinado meio natural. Por exemplo, uma área com relevo acidentado e com densa vegetação arbustiva ou arbórea terá uma maior capacidade de absorção visual que uma área plana e com cobertura vegetal escassa (Cerro, 1993).

\section{Capacidade material}

- Refere-se a características geográficas, geológicas, topográficas e botânicas associadas às condições de segurança oferecidas aos turistas. Isso quer dizer, por exemplo, que o acesso ao cume de altas montanhas ficará restrito ao turismo especializado nesse tipo de esporte. Em outros lugares, como cascatas ou cavernas, é necessário assegurar percursos, sinalização e equipamentos adequados ao ingresso de turistas que descartem qualquer perigo. Ao mesmo tempo, a adequação de capacidade material deve evitar que o excesso de pessoas e de instalações de segurança venha afetar a paisagem, agregando-lhe uma série de artefatos que alterem a sua unidade natural (Boullón, 1997).

\section{E. Capacidade física}

- Está relacionada ao número máximo de "unidades de uso" que podem ser fisicamente absorvidas numa determinada área, como locais para estacionamento e circulação de veículos, para a permanência de pessoas etc. Dessa forma, a determinação da capacidade de carga física é o estágio inicial, a partir do qual a avaliação da capacidade de carga recreativa se processa (Sowaman, 1987).

\section{F. Capacidade econômica}

- Está relacionada a situações em que um recurso é simultaneamente utilizado para atividades de recreação ao ar livre e para atividades econômicas. O interesse, nesse caso, está em estabelecer níveis aceitáveis de uso recreativo que não interfiram indevidamente em atividades de caráter não recreativo, no sentido de reduzir a viabilidade econômica do recurso (Sowaman, 1987).

\section{G. Capacidade ambiental}

- Relaciona-se ao nível máximo de uso turístico da destinação, antes que os turistas notem um declínio da atratividade da área e se desloquem para outras destinações. Tal capacidade poderá variar de acordo com o tipo de atividade turística, com as condições do tempo e com fatores sazonais (Mason, 1990).

Ainda que os distintos enfoques tenham sido separados e/ou agrupados em categorias diferenciadas, o que comprova a sua abrangência, persistem similaridades e sobreposições de conteúdos e significados na base conceitual dos mesmos, evidenciando com isso a complexidade que envolve o trato desse tema na sua justa dimensão.

\section{A gestão sustentável da recreação e do turismo em áreas naturais}

Se até o momento a idéia de "capacidade de carga" foi exposta em sua dimensão conceitual e desdobrada na sua abrangência de enfoques, colocando-se clara- 
mente e acima de tudo como um marco paradigmático, cabe agora contextualizá-la no campo das estratégias de gestão da demanda turística e recreativa no meio ambiente natural, sobre o qual recai grande parte das atençōes e dos esforços de planejamento e gestão da demanda turística e recreativa no mundo todo.

Nesse sentido, a "capacidade de carga" passa a figurar como conceito operacional, com seus desdobramentos metodológicos aplicáveis ao processo de gestão de visitantes e do turismo, visando reduzir impactos indesejados especialmente nas áreas naturais protegidas, destinos preferenciais do turismo na natureza em todo o mundo. No Brasil, correspondem às áreas abrigadas no Sistema Nacional de Unidades de Conservação e, obviamente, às praias litorâneas, estas consideradas genericamente e não necessariamente no contexto das áreas protegidas. Como tal, a partir do final da década de 1960, e sobretudo na década de 1970, o conceito de "capacidade de carga" se materializou em um corpo de procedimentos com critérios analíticos e parâmetros mensuráveis, visando definir limites para o nú mero de visitantes presentes nesses espaços naturais.

Desde então, e a partir da experiência obtida nesse processo, ao mesmo tempo que a própria metodologia de determinação da capacidade de carga foi incorporando novas variáveis de análise na tentativa de lhe conferir maior consistência, surgiram novas propostas metodológicas e processuais que, embora historicamente possam ser consideradas desdobramentos metodológicos do marco conceitual da capacidade de carga, representam estratégias evolutivas e alternativas a esse modelo, concebidas e estruturadas para, justamente, superar as limitações apontadas por observadores e críticos do modelo no que se refere à sua aplicabilidade e efetividade.

Essas estratégias - algumas surgidas ainda na década de 1980 -, no seu conjunto, representam atualmente um referencial técnico-metodológico importante em alguns casos, contento uma metodologia mais definida; em outros, se configurando como um marco orientador do processo de gestão mais flexível na forma de um roteiro de ações e medidas articuladas. Sendo assim, os principais modelos e referências metodológicas a serem aqui destacados são os seguintes:

- Capacidade de Carga (Carryng Capacity) e padrões numéricos;

- Espectro de Oportunidades Recreativas (The Recreation Opportunity Spectrum-ROS);

- Limites Aceitáveis de Alteração (Limits of Acceptable Change - LAC);

- Gestão do Impacto de Visitantes (Visitor Impact Management - VIM);

- Processo de Gestão da Visitação (Visitor Activity ManagementProcess-VAMP);

- Proteção aos Recursos e à Experiência dos Visitantes (Visitor Experience and Resource Protection - VERP);
- Modelo de Otimização da Gestão Turística (Tourism Optimization Management Model - TOMM);

- Distância Pessoal (Bolha Ecológica).

\section{Capacidade de carga e padrões numéricos}

O que se apresenta a seguir são apenas exemplos sintéticos e ilustrativos dos métodos que investem no aspecto quantitativo e na definição de padrões de densidade de ocupação de espaços turísticos dentro do espectro da capacidade de carga. Embora a natureza desses métodos conduza a um resultado numérico, este nem sempre representa a resposta final à determinação da capacidade de carga, podendo também se prestar como etapa ou indicador quantitativo de estratégias de gestão mais abrangentes, como se verá mais adiante.

\section{A) O método de Cifuentes}

A Fundação Neotrópica da Costa Rica, por meio do Centro de Estudos Ambientais e Políticos - CEAP, com base na metodologia desenvolvida por Cifuentes ${ }^{4}$ e estabelecida para a Reserva Biológica de Carara, desenvolveu procedimentos que levam a resultados quantitativos em termos de número de visitantes por período de visita. O processo de determinação numérica da capacidade de carga possui três níveis sucessivos, a saber: a capacidade de carga física, a capacidade de carga real e a capacidade de carga efetiva, sendo, ainda, precedido de alguns estudos preliminares sobre os objetivos de manejo e o zoneamento da área protegida em questão.

- Capacidade de Carga Física - É a capacidade do destino turístico calculada com base nos seguintes parâmetros:

- espaço ocupado por cada visitante (um metro quadrado);

- os tipos de visita (número de visitantes por grupo, distância entre grupos, tempo necessário para a visita);

- espaço disponível na área, incluindo os critérios de manejo anteriormente considerados;

4. CIFUENTES, M. et al. 1990. Capacidad de carga turística de la reserva biológica Carara. San José, Servício de Parques Nacionales y Centro Agronómico Tropical de Investigación y Enseñanza. (Obs.: o método de Cifuentes tem origem em experiências originalmente desenvolvidas nas Ilhas Galápagos, Equador.) 
- Capacidade de Carga Real - Uma vez determinada a capacidade de carga física, esta poderá ser afetada por fatores ambientais e ecológicos, como pluviosidade, intensidade de insolação, erodibilidade dos solos, vulnerabilidade da fauna e flora, acessibilidade etc. Dessa forma, a constatação da incidência de tais fatores poderá reduzir a capacidade anteriormente determinada para a área em questão e, conseqüentemente, os mesmos passam a ser aplicados como fatores de correção sobre o valor da CCF anteriormente determinado;

- Capacidade de Carga Efetiva - É a capacidade de carga relacionada com a capacidade de manejo e controle por parte dos responsáveis pela gestão dos destinos turísticos. A CCE depende de uma série de critérios e estimativas de caráter subjetivo em termos de apoio governamental, respaldo jurídico, suporte econômico; e outros de caráter objetivo, como disponibilidade de pessoal, formação de equipe, instalações e recursos financeiros. Sua determinação, como se vê, não é exata, mas consensual e subjetiva.

Neste método, a capacidade de carga é determinada numericamente por meio de formulações matemáticas, ou seja, a partir da definição da Cc Física, e após a aplicação nesta de fatores de correção (representados numericamente) relativos aos condicionantes identificados durante o estudo da Cc Real e cc Efetiva, chega-se ao número de visitantes em um determinado período e em uma determinada área. Cada lugar específico (sítio) com potencial para visitas dentro de uma área natural deverá ter a sua capacidade de carga determinada, sendo necessário estabelecer relações de capacidade entre todos os sítios de visita de uma área natural.

Os fatores de redução da capacidade de carga relacionados ao clima (chuvas, secas) ou a fatores biológicos (acasalamento e reprodução das espécies) deverão ser considerados no seu aspecto de estacionalidade, ainda que no cálculo da capacidade de carga física tais fatores tenham sido considerados para a determinação de um valor diário de visitantes a ser extrapolado para o ano inteiro. Os responsáveis diretos pelo manejo das áreas naturais deverão buscar formas de compatibilizar o valor global de Cc com os aspectos de manejo específico para situações localizadas e para épocas diferenciadas.

\section{B) A formulação de Boullón}

Para o contexto latino-americano, Boullón (1997) apresentou uma proposta, também numérica, para a determinação da capacidade de carga turística de uma determinada área (não necessariamente natural), e que é obtida pelo re- sultado da divisão do valor relativo à dimensão da área utilizada pelos visitantes/ turistas por um valor padrão. Esse valor padrão representa o espaço (metro quadrado/pessoa) adotado teórica ou experimentalmente como capacidade territorial limite para cada usuário da referida área.

A seguir, calcula-se o total de visitas diárias (capacidade de carga/dia) simplesmente multiplicando o valor da capacidade obtido anteriormente por um coeficiente de rotatividade, o qual, por sua vez, é obtido mediante a divisão do valor do tempo em que a destinação está aberta à visitação ou uso, pelo tempo médio de duração das visitas calculado para essa localidade. Lozato Giotard ${ }^{5}$ apresenta uma formulação equivalente à de Boullón, e que foi adaptada no Brasil por Ruschmann (1997) para a determinação da capacidade de carga turístico-recreativa em praias do Brasil.

\section{C) A formulação de Salinas}

Uma outra formulação numérica de capacidade de carga proposta por Sa$\operatorname{linas}^{6}$ e citada por Chaves e Rodrigues (1993) é constituída, igualmente, de uma fórmula matemática na qual a capacidade de carga turística é função de alguns coeficientes representativos de fatores como a fragilidade da paisagem, a funcionalidade recreativa e a categoria turística do local.

\section{D) Densidades e padrões de uso turístico (Cerro, 1993; Chávez e Cid, 1991; Gómez et al., 1993)}

Apresentam-se a seguir alguns tipos de indicadores de uso baseados em critérios de densidade de usuários, os quais poderão estar referenciados em relação à unidade territorial, ao tipo de atividade recreativa, ao tipo ecológico de área natural ou, ainda, ao zoneamento quando em áreas protegidas. Os números e padrões assim definidos resultam de processos distintos de determinação, podendo ser meramente de natureza empírico-subjetiva, ou obtidos por critérios técnicos e experimentais. Em ambos os casos, o que irá determinar sua validade é a eficácia do processo para os quais estão se prestando.

5. LOZATO GIOTARD, J. P. 1992. Geographical rating in tourism development. Tourism Management. London: Butterworth-Heinemann, v. 13, no 1 .

6. SALINAS, E. 1986. Evaluación de los paisajes de Cuba para el turismo. 152 p. Tesis (Doctorado). Universidad Estatal de Kiev. 
- Densidade de usuários recomendada para praias

A determinação teórica do número de usuários por unidade territorial (metro quadrado) recomendado para praias consiste num parâmetro orientador para o controle da capacidade de carga turística em praias. Nesse sentido, podem ser identificadas várias determinações para as mais distintas praias pelo mundo. As referidas densidades recomendadas podem variar, por exemplo, de 1,7 metro quadrado (Países Baixos) a 25 metros quadrados por usuário (França). Um dos fatores determinantes dessa notável diferença tem sido a maior ou menor distância da praia considerada em relação aos núcleos populacionais, onde a condição de maior afastamento acaba por determinar uma menor densidade e vice-versa.

- Densidade por tipo de atividade

Em vez do número de pessoas, o tipo de atividade recreativa pode determinar a densidade de uso recomendada, como a que preconiza o Serviço Americano de Pesca eVida Selvagem nos seguintes exemplos: passeios a pé ( 0,5 hectare/visitante); caiaquismo ( 1 quilômetro fluvial/10 visitantes), e percursos eqüestres ( 120 metros/visitante).

- Densidade por tipo de área

A característica ecológica da área natural pode ser o critério definidor da quantidade de pessoas a visitá-la. Neste caso, tem-se que uma área de savana pode comportar de 12 a 15 visitantes/hectare; uma área com manguezais, de 10 a 12 visitantes/hectare; e uma área com floresta semidecidual, de 15 a 18 visitantes/hectare.

- Densidade por tipo de zona em áreas naturais protegidas

Como as áreas naturais protegidas em condições normais de planejamento são divididas em zonas de uso, tem-se que para a zona de uso extensivo recomenda-se 20 turistas/quilômetro quadrado; e zonas de uso intensivo, 500 turistas/quilômetro quadrado.

\section{Distância pessoal ou bolha ecológica}

O conceito de "distância pessoal", também chamado de "bolha ecológica", é apresentado por Boullón (1997) como forma de superar as limitações de aplicação dos principais métodos de capacidade de carga turística e recreativa em áreas de uso intensivo, caso da maioria das praias turísticas, já que na sua maior partem os métodos são concebidos para áreas naturais protegidas, geralmente de grandes dimensões territoriais.

Para o autor, nessas destinações, onde o nível de exploração já é e deve continuar a ser intensivo, não adianta considerar a capacidade de carga ecológica, uma vez que o ambiente natural original já não existe mais. Resta apenas buscar uma recuperação da qualidade ambiental do entorno urbano que está associado ao recurso "praia" considerado. Porém, será necessário estabelecer limites para controlar o número máximo de pessoas a ocupar o espaço simultaneamente, em função de suas necessidades como usuárias do recurso.

Essa condição se dará pelo advento do conceito de capacidade de carga material (eventuais restrições impostas pelas condições do solo e da água) e, especialmente, da capacidade de carga psicológica. É nesse momento, então, que se introduz o conceito de distância pessoal, também chamado simbolicamente de bolha ecológica, cuja definição, em essência, é a seguinte: "Uma área determinada, dotada de fronteiras invisíveis que circundam o corpo da pessoa, e na qual os intrusos não devem penetrar". (Henri Hedger In: Boullón, 1997).

Sendo assim, para Boullón, a distância pessoal apresenta objetivamente dois tipos de relação, a saber: a relação homem-homem e a relação homem-ambiente. A partir dessa condição universal, e ao se considerar o conjunto de atividades passiveis de serem realizadas pelos turistas em qualquer tipo de ambiente, admitem-se quatro tipos de distâncias pessoais: isoladas (caminhadas, pesca); de proximidade (viagens coletivas, feiras); de conjunto (jogos em equipe), e de contato (dança). Somente as três primeiras são aplicáveis a situações em que se deseje determinar a capacidade de carga psicológica em ambientes naturais (no caso, as praias), ou seja, por meio da investigação do tamanho que assumem as "bolhas ecológicas" individuais e de grupo, em função das classes de turistas e das atividades recreativas por eles desenvolvidas.

O conceito de "distância pessoal" encontra-se certamente localizado no vasto campo de conhecimento e investigação que é a psicologia ambiental: "Estudo do relacionamento molar entre o comportamento e a experiência humana e o ambiente construído e natural" (Bell et al., 1996). Em seu âmbito estuda-se o espaço pessoal e a territorialidade, cujo entendimento e domínio metodológico podem contribuir para o avanço das abordagens em relação à própria capacidade de carga psicológica/perceptiva dos usuários de espaços recreacionais e turísticos, especialmente aqueles caracterizados pelo fenômeno da aglomeração, que são as praias preferenciais do turismo de massa.

\section{Modelos para a gestão do uso público em áreas naturais protegidas}

Para tentar superar as limitações presentes nos métodos tradicionais de capacidade de carga, a partir da década de 1980 surgiram novas propostas de gestão da 
visitação em áreas protegidas, destacando-se, a seguir, as mais conhecidas e usadas em várias partes do mundo (Eagles, P. F. J. et al., 2002).

\section{Espectro de Oportunidades Recreativas \\ (Recreation Opportunity Spectrum - ROS)}

Foi desenvolvido por pesquisadores do Serviço Florestal e da Agência de Gestão Territorial dos Estados Unidos para atender a conflitos crescentes gerados pelo uso recreativo de recursos naturais escassos e, também, às diretrizes legislativas que necessitavam de um referencial de abordagem integrada e abrangente do planejamento de recursos naturais. O modelo é aplicável tanto em áreas naturais protegidas como, de forma mais geral, no planejamento da paisagem, porém, sempre onde haja uma demanda pelo turismo e a recreação na natureza.

O modelo resulta de um processo de planejamento com etapas concatenadas que incluem, desde o inventário das condições físicas, sociais e aspectos de administração que afetam a experiência do visitante, até o monitoramento do processo. Nele se definem seis classes de oportunidades recreativas que compreendem desde áreas primitivas até árcas urbanas, estabelecendo-se também parâmetros e diretrizes de manejo de oportunidades recreativas nas seis classes de oportunidade, com base em fatores e indicadores como: acesso e isolamento da área, encontros sociais, impactos dos visitantes e características visuais da paisagem.

Em essência, o método busca entender as características dos visitantes, suas expectativas diante dos distintos ambientes e as atividades que desejam realizar nesses ambientes e, a partir daí, ajustar esses dados às restrições ecológicas dos ambientes e às facilidades que apoiarão o desencadear da demanda recreativa na sua dimensão mais ampla. $\mathrm{O}$ Ros resulta, assim, numa grande matriz de zoneamento recreativo e, como tal, além de prestar-se por si mesmo como instrumento de gestão, vem sendo incorporado a outros modelos de planejamento, como LAC, VIM e VAMP em suas respectivas etapas metodológicas.

\section{Limites Aceitáveis de Alteração}

(Limits of Acceptable Change - LAC)

Foi também desenvolvido pelo Serviço Florestal Americano para atender ao manejo dos impactos da recreação, sendo considerado uma extensão do ROS, que foi então re-elaborado no âmbito de um contexto mais claro de planejamento.
A expressão LAC indica que a utilização de uma área com finalidades turísticas pode estar causando impactos ou pode causá-los no futuro. Nesse sentido, as decisões de manejo consistem em estabelecer até que ponto as alterações são aceitáveis, além de não permitir que aconteçam deteriorações dentro das classes de oportunidade de uso.

O LAC reconhece as vertentes sociais e ecológicas nos impactos produzidos pelas atividades recreativas, e sua metodologia envolve tanto os gestores dos recursos para a recreação e o turismo quanto os que possuem interesse econômico nessas atividades. Entre todos os modelos de gestão de capacidade de carga atuais, o método é visto como o que possui uma adoção mais generalizada e uma maior aceitação.

O LAC consiste num processo envolvendo nove etapas sucessivas e interconectadas, sendo que a segunda etapa corresponde exatamente à definição das Classes de Oportunidades Recreativas do ROs. Seu produto final é um plano estratégico e tático para uma determinada área, baseado em limites definidos de alterações ou mudanças (no meio natural e social) aceitáveis para cada uma das classes de oportunidade recreativa, com indicadores de alteração que podem ser utilizados para monitorar as condições ecológicas e sociais do contexto em questão. Trata-se de definir as diferentes zonas que poderão absorver uma ampla gama de oportunidades, desde a proteção absoluta (áreas primitivas) até as mais variadas experiências, uma vez compatíveis com os objetivos de manejo da área natural em questão. $\mathrm{O}$ modelo considera também a inclusão de usos não turísticos para a área, como o extrativismo, a exploração mineral, pastagens, agricultura etc.

O LAC consiste, assim, em um sistema técnico de planejamento, proporcionando um referencial sistemático para a tomada de decisões de gestão. Atua, portanto, na dicotomia uso/impacto, no contexto do turismo e da recreação e, com isso, implica uma reformulação do conceito de capacidade de carga, preso em sua origem, ao determinante uso/não uso. Dessa forma, define os impactos associados aos distintos níveis de proteção ambiental que se desejam para cada uma das diferentes zonas de uma determinada área ou região, oferecendo uma base de orientação nas mudanças ecológicas e sociais aceitas por todos os envolvidos como coerentes e apropriadas, tendo em vista os diversos tipos de oportunidades recreativas a desenvolver (Wearing \& Neil, 2000).

\section{Gestão do Impacto de Visitantes \\ (Visitor Impact Management - vIM)}

Esse modelo foi desenvolvido pelo Serviço Nacional de Parques e pela Associação de Conservação dos Estados Unidos, apresentando uma metodologia de 
identificação e monitoramento de impactos similar ao LAC, na medida em que se baseia em indicadores e padrões para a definição de impactos considerados inaceitáveis, buscando, porém, o entendimento das suas causas geradoras e identificando estratégias de gestão dessas causas no âmbito do planejamento e do desenho de políticas concretas.

O viM procura estabelecer níveis de impacto e critérios de manejo para condições flexíveis e flutuantes de visitação, e a sua ênfase está na definição dos objetivos de manejo para cada lugar ou zona no interior das áreas naturais. A partir daí, é determinada uma série de impactos mensuráveis (compactação do solo, erosão, alteração da vegetação, desaparecimento da fauna), com os quais se verifica se a área está cumprindo com os objetivos de manejo para ela determinados ou se está havendo deterioração significativa. Com base na situação verificada são definidas medidas de manejo apropriadas, tais como:

- Limitação temporária do acesso a determinados sítios em função da tolerância de espécies da fauna a ruídos e outras perturbações de origem humana;

- Monitoramento dos possíveis impactos decorrentes da concentração e aumento de visitantes sobre os sítios com fragilidade ecológica;

- Programação de meios para a interpretação da natureza, alternativos à presença dos visitantes nas áreas críticas (centro de exposições, quiosques de informação, material escrito, palestras);

- Alternância de sítios para a visitação, dentro da mesma área natural, com características ecológicas semelhantes.

O modelo vim também vê o conceito de capacidade de carga dentro de um contexto de gestão empresarial mais global. O ponto-chave que o diferencia metodologicamente do modelo LAC é a não utilização de classes de oportunidades recreativas (Kuss et al, 1990; Wearing \& Neil, 2000; Eagles, P. F. J. et al., 2002).

\section{Processo de Gestão da Visitação \\ (Visitor Activity Management Process - vamp)}

Foi criado no âmbito do Sistema de Planejamento e Gestão de Parques do Canadá e tem por objetivo oferecer um arcabouço para a identificação e gestão de oportunidades para os visitantes no interior deses parques. O modelo do vamp é uma ampliação do vIM e, em vez de concentrar-se na gestão dos recursos (limites aceitáveis de modificação dos ecossistemas, paisagens etc.), funciona complemen- tarmente com enfoque voltado para a gestão dos usuários desses recursos, subsidiando programas de interpretação ambiental e orientando os demais serviços oferecidos aos visitantes dos parques, acompanhando as suas expectativas e grau de satisfação (Wearing \& Neil, 2000).

Dessa forma, o vamp também incorpora os princípios do Espectro de Oportunidades Recreativas ao determinar oportunidades de recreação aos visitantes, podendo, da mesma forma, incorporar facilmente os princípios do VIM, LAC e VERP. (Wearing \& Neil, 2000; Eagles, P. F. J. et al., 2002).

\section{Modelo de Otimização do Turismo \\ (Tourism Optimization Model - TOM)}

Foi gerado na Austrália não só para o sistema de parques como para qualquer destinação de turismo na natureza. O referencial metodológico de partida deste modelo é o LAC, visando controlar e administrar a atividade turística a partir de uma perspectiva de rendimentos (econômicos) ótimos porém sustentáveis, colocando em segundo plano o enfoque em níveis máximos de uso ou na capacidade de carga.

A adoção do modelo том implica, entre outros, identificar políticas setoriais, os valores da comunidade, as características do produto, as tendências do mercado e outros aspectos condicionantes do crescimento da atividade turística em uma região. Identifica, também, indicadores ecológicos, sociais, ambientais e os limites de uso aceitáveis. Nesse processo, destaca-se a identificação dos rendimentos econômicos atuais e futuros tanto do setor turístico como de outros setores implicados, bem como a preocupação com a reversão de situações desfavoráveis nesse sentido.

\section{Proteção aos Recursos e à Experiência dos Visitantes \\ (Visitor Experience and Resource Protection - VERP)}

Criado também pelo Serviço Nacional de Parques dos EUA, compreende a prescrição de um futuro desejável tanto para os recursos quanto para as condições sociais de sua utilização, definindo que níveis de uso são apropriados, onde, quando e como.

A exemplo da maior parte dos modelos anteriores, é um processo de planejamento que envolve etapas sucessivas e interconectadas de ações e análises, adotando também indicadores e padrões para o acompanhamento de mudanças nos 
recursos e percepções dos usuários. A ênfase do modelo reside em decisões estratégicas concernentes à concepção de capacidade de carga, ou seja, baseado na valorização da qualidade dos recursos e na qualidade da experiência do visitante. O produto final é uma série de prescrições para o manejo do zoneamento do parque, definindo condições futuras desejáveis, com indicadores e padrões de monitoramento.

Similar ao VAMP, é um processo que orienta a análise dos recursos com base no conhecimento do seu significado e sensibilidade, e a análise das oportunidades recreativas é orientada por dados sistematizados da experiência e da percepção de visitantes. A ênfase da gestão de todo o processo é o zoneamento.

\section{O alcance e as limitações dos modelos de gestão}

Tomados em seu conjunto, os modelos ROS, LAC, VIM, VAMP, TOM e VERP apresentam características muito similares ou equivalentes em termos de áreas de aplicação. Nesse sentido, todos possuem virtudes ou atributos positivos para a gestão de visitantes, podendo-se destacar:

- São aptos para a avaliação do impacto de visitantes e a sua minimização;

- Consideram as múltiplas causas subjacentes aos impactos;

- Facilitam a seleção de uma variedade de ações para a gestão ou manejo;

- Produzem decisões voltadas à proteção dos recursos;

- Discernem informações técnicas (objetivas) das de julgamentos de valor (subjetivas);

- Estimulam o envolvimento do público e o compartilhamento do conhecimento;

- Incorporam a utilização dos recursos locais e o imperativo de sua gestão.

Porém, ao se verificar as possíveis limitações ou atributos negativos, apresentam entre si diferenças de escala ou de grau de limitação em relação a dois aspectos principais:

- A necessidade de investir no planejamento;

- A efetividade baseada, sobretudo, na experiência.

Nesse sentido, o vim é o único modelo que apresenta uma baixa limitação para o primeiro aspecto (planejamento), enquanto os demais, sobretudo o том e o VAMP, apresentam uma elevada limitação para o mesmo aspecto. Já em relação ao segundo aspecto (efetividade), o VIM, o VAMP e o VERP apresentam uma baixa limitação, enquanto o LAC e o ROS, especificamente, apresentam uma elevada limitação (Eagles, P. F. J. et al., 2002).

Na verdade, a dimensão dos desafios surgidos com a adoção desses modelos, que são abordagens inovadoras e ambiciosas na perspectiva da gestão do uso público dos recursos naturais para o turismo e a recreação, perpassa as seguintes questões que podem se constituir em limitações:

- Eles requerem suporte de pessoal, fundos (capital) e tempo para a sua implementação;

- Freqüentemente existem lacunas de conhecimento científico sobre impacto de visitantes, cujo julgamento tem que ser feito de forma subjetiva ou baseado em informações limitadas;

- As ações e medidas de gestão requeridas nem sempre são tomadas, mesmo quando os limites ecológicos e sociais foram demasiadamente excedidos, por conta da falta de recursos humanos, ou da falta de vontade e coragem de adotar medidas mais fortes e opções de difícil aceitação.

\section{Avancos constatados e desafios a enfrentar}

A partir do momento que se constatou, pela experiência, a ineficácia da limitação pura e simples do número de visitantes nas áreas naturais protegidas como forma de controlar os impactos sobre o ambiente biofísico dessas áreas, percebeu-se que o conceito tradicional de capacidade de carga centrado no foco "quantos são muitos" (Lindberg et al. In: Magro, 1999), já não era capaz de dar suporte consistente e efetivo a uma gestão eficiente nesse aspecto.

Daí surgirem os esforços de atualização e ampliação do conceito e do alcance metodológico de capacidade de carga, com o novo foco em "quais são as condições desejadas", já agora contemplando e buscando equilibrar os "desejos" múltiplos tanto dos protetores dos recursos (ambientalistas, conservacionistas, responsáveis legais), como dos visitantes (sua demanda e expectativa) e, quando fosse o caso, das populações envolvidas e de suas aspirações socioeconômicas.

Com isso atingiu-se, sem dúvida, um patamar mais realista, superando, assim, as limitações de alcance do modelo tradicional de CC, que primava unicamente pela formulação técnica desse modelo, e pelo estabelecimento de padrões quantitativos alheios aos fatores psicológicos, sociais, político-institucionais e econômicos que permeiam todos os interesses que intervêm de fato no caso. 
Porém, mesmo nos países dotados de condições estruturais e financeiras favoráveis à plena gestão do controle dos impactos e dos demais objetivos de manejo das áreas naturais protegidas, a adoção dos atuais modelos (LAC, VIM, VAMP, TOM e VERP) com todos os seus desdobramentos metodológicos e em toda a sua abrangência tem-se mostrado um desafio permanente aos seus protagonistas, exatamente no aspecto da gestão dos distintos interesses e influências que intervêm no desenrolar desse processo. Essa rotina, infelizmente, não se aplica ainda ao Brasil, onde sequer foram superadas as limitações e circunstâncias adversas (escassez e despreparo de pessoal, falta de verbas, desestruturação institucional etc.) para o estabelecimento das condições básicas de manejo das áreas naturais, como, por exemplo, a regularização fundiária, a delimitação territorial, a implantação de infra-estrutura e a fixação de pessoal. Contudo, já é possível constatar casos pontuais, porém crescentes, de estudos científicos por iniciativa acadêmica, destacando-se os trabalhos de Takahashi (1998), Magro (1999) e outros mais recentes em algumas Unidades de Conservação, e que estão apontando na direção da gestão dos impactos com esse enfoque abrangente.

Por um lado, se é possível contar com a existência de um amplo espectro de alternativas metodológicas e de modelos de gestão do impacto de visitantes no âmbito das áreas naturais protegidas, por outro, quando se trata de considerar espaços de recreação e turismo não protegidos na forma de Unidades de Conservação, como as praias, ou outros espaços com recursos naturais demandados para a mesma finalidade, esses modelos têm a sua aplicação, se não inviabilizada, altamente dificultada, já que foram concebidos e estruturados para aplicação em espaços protegidos na forma de Unidades de Conservação ou sob regime de ordenamento territorial efetivo, o que permite ou facilita não só o controle do afluxo e do comportamento de visitantes, bem como a limitação de outras atividades humanas indesejadas.

Sendo assim, fica evidente entre nós a carência de metodologias e modelos passíveis de aplicação e de êxito nos demais espaços naturais que se situam fora dos sistemas legais de proteção efetiva. É o caso notório das destinações preferenciais do turismo de massa, sobretudo o turismo de sol e mar, em que o afluxo maciço de usuários é inevitável. Nesse caso, os referenciais existentes, baseados em padrões de densidade e ocupação quantitativa ${ }^{7}$, embora se prestem como indicadores úteis para estudos, não são passiveis de efetividade, já que não há como proibir legalmente e coibir fisicamente o afluxo de pessoas a esses espaços. As

7. No Brasil, já na década de 1970, a EMBRATuR difundia o "Projeto Turis", com padrōes recomendados de densidade e distribuição dos usuários de praias. praias que ainda mantêm baixos a moderados níveis de uso recreativos são aquelas com acesso dificultado ou mais distantes dos centros urbanos e dos pólos turísticos emissores.

Portanto, há que se buscar alternativas de controle de impactos para esses casos, parecendo plausível a proposta de ampliação e aprofundamento dos estudos de capacidade de carga psicológica/social/perceptiva, a partir de referenciais teóricos como a distância e o espaço pessoal (Boullón, 1997; Bell et. al., 1996). Os resultados desse tipo de investigação aplicada, incorporados ao bom senso e à sensibilidade de gestores e tomadores de decisão, poderão favorecer a melhor adequação entre espaços e atividades, orientar a distribuição e a dispersão de usuários, permitir o zoneamento dos espaços de lazer, entre outras alternativas de gestão, que garantam a satisfação da experiência recreativa com níveis razoáveis de qualidade ambiental e com viabilidade social, política e econômica.

\section{Referências bibliográficas}

BELL, P. A.; GREENE, T. G.; FISHER, J. D. \& BAUM, A. 1996. Environmental psycology. 4.ed. Orlando: Harcourt Brace \& Company.

BOO, E. 1990. Ecoturismo: potenciales y escollos. Washington, D.C: WWF/Conservation Foundation.

BOULLÓN, R. C. 1997. Planificación del espacio turistico. 3.ed. México: Trilhas.

BOULLÓN, R. C. \& OTERO, A. et al. 1995. Estandares para las actividades del tiempo libre. In: congresso internacional. de geografia e Planejamento do turismo. 1995. São Paulo. Anais. São Paulo: Departamento de Geografia, USP.

CEAP - Centro de Estudios Ambientales y Politicas. 1992. Analisis de capacidad de carga para visitación en las areas silvestres de Costa Rica. San José: Funcadión Neotropica.

CEBALLOS-LASCURAIN, H. 1996. Tourism, ecotourism and protected areas: the state of naturebased tourism around the world and guidelines for its development. Gland, Switzerland and Cambridge, England: IUCN.

CERRO, F. L. 1993. Técnicas de evaluación del potencial turístico. Madrid: MCYT. (Serie Libros Turisticos).

CHÁVEZ, E. S. \& CID, O. C. 1991. La zonificación funcional y la planificación turística en áreas protegidas. Revista Latinoamericana de Turismo. Buenos Aires: Centro de Investigaciones y Estudios Turísticos, v.1, $\mathrm{n}^{\mathrm{Q}} 4$

EAGLES, P. F. J.; McCOOL, S. F. \& HAYNES, C. D. 2002. Sustainable tourism in protected areas: guidelines for planning and management. Best Practice Protected Areas Guidelines Series n ${ }^{\circ}$. UK: Cardiff University; UNEP; WIO; IUCN; WCPA.

GÓMEZ, M. J. M.; ROSABAL, P. M.; CHÁVEZ, E. S.; FERNÁNDEZ, B. \& DORADO, Y. 1993. Planificación y desarrollo del ecoturismo. Estudios Turísticos. Madrid, n 119-120, p.39-59. 
KUSS, F. R.; GRAEFE, A.R. \& VASKE, J. J. 1990. Visitor impact management: a review of research. v. 1. Washington, D.C.: National Parks and Conservation Association.

MAGRO, T. C. 1999. Impactos do uso público em uma trilha no planalto do Parque Nacional do Itatiaia. Tese (Doutorado). Escola de Engenharia de São Carlos - usp, São Carlos.

MASON, P. 1990. Tourism: environment and development perspectives. London: WwF.

RUSCHMANN, D. M. et. al. 1997. A proteção ambiental como instrumento de estratégia empresarial: o caso da Ilha João da Cunha - SC. In: IV ENCONTRO NACIONAL SOBRE GESTÃo EMPRESARIAL e meio ambiente. 1997. São Paulo. Anais. São Paulo: uSp/FGV, p. 92-106.

SOWAMAN, M. R. 1987. A procedure for assessing recreacional carrying capacity of coastal resort areas. Landscape and Urban Planning. Amsterdan: Elsevier Science Publishers. B.v. nº 14, p. 331-334.

TAKAHASHI, L. Y. 1997. Limite aceitável de câmbio - LAC: manejando e monitorando visitantes. In: Congresso brasileiro de unidades de ConservaÇão. 1997. Curitiba. Anais. v. 1. Curitiba, UFPR, p. 445-464.

1998. Caracterização dos visitantes, suas preferências e percepções e avaliação dos impactos da visitação pública em duas Unidades de Conservação do Estado do Paraná. 129 f. Dissertação (Mestrado). UFPR/SCA, Curitiba.

WAGAR, J.A. 1964. The carrying capacity of wildlands for recreation. Forest Science Monograph, $\mathrm{n}^{\mathrm{o}}$ 7. Washington D.C.: Society of American Foresters.

WEARING, S. \& Neil, J. 2000. Ecoturismo: impacto, tendencias y posibilidades. Madrid: Sintesis.

Recebido em 11/05/2004.

Aprovado em 04/08/2004. 